\title{
Synthesis, Antimicrobial Activity and In Vivo Fluorine NMR of a Hexafluorinated Derivative of Tilmicosin ${ }^{\dagger}$
}

\author{
Lawrence C. Creemer,${ }^{*, a}$ Herbert A. Kirst, ${ }^{a}$ Thomas R. Shryock, \\ JACK B. CAMPBELL ${ }^{b}$ and ANDREW G. WEBB ${ }^{c}$

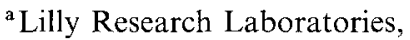 \\ P.O. Box 708, 2001 West Main Street, Greenfield, IN 46140, U.S.A. \\ ${ }^{\mathrm{b}}$ Lilly Research Laboratories, Lilly Corporate Center, \\ Indianapolis, IN 46285, U.S.A. \\ ${ }^{\mathrm{c}}$ Department of Electrical and Computer Engineering, University of Illinois, \\ 405 N. Mathews Avenue, Urbana, IL 61801, U.S.A.
}

(Received for publication February 24, 1995)

\begin{abstract}
A new fluorinated analog of tilmicosin was synthesized by the reductive amination of desmycosin with 3,5-bis(trifluoromethyl)piperidine. Despite an apparently small change in structure, the fluorinated analog had much less in vitro antimicrobial activity than tilmicosin and it failed to protect 3-day old chicks against a Pasteurella multocida challenge at $64 \mathrm{mg} / \mathrm{kg}$ sc. In a preliminary in vivo fluorine NMR experiment in a female Sprague-Dawley rat, a ${ }^{19} \mathrm{~F}$ NMR signal was detected in the liver one hour after ip administration of the fluorinated compound. Therefore, although this fluorinated derivative had less antimicrobial activity than tilmicosin, it may nevertheless provide a suitable model of tilmicosin for pharmacokinetic studies using in vivo fluorine NMR.
\end{abstract}

The use of fluorine NMR $\left({ }^{19} \mathrm{~F}\right.$ NMR) as a tool to investigate the disposition of drugs in vivo is a potentially important method for the non-invasive study of pharmacokinetics. The low level of background fluorine found in the body allows the distribution of a fluorinated compound to be followed over time by repeated assays on the same animal, which need not be sacrificed to obtain the data. For this purpose, it is necessary to synthesize fluorinated analogs whose biological activity and pharmacokinetics accurately model the parent drug.

High tissue concentrations are desirable for obtaining a strong in vivo ${ }^{19} \mathrm{~F}$ NMR signal. Macrolide antibiotics are known to achieve very high tissue concentrations within a short time after administration. ${ }^{1)}$ A convenient procedure to measure macrolide concentrations in tissues and organs and to follow their uptake, distribution, and elimination would provide a very valuable research tool. Such studies would complement existing methods and allow a more thorough understanding of macrolide penetration and accumulation throughout the body.

Tilmicosin (1) is a new macrolide antibiotic approved for treating respiratory disease in cattle. ${ }^{2)}$ In order to explore this biological application of spectoscopy, a fluorinated analog of tilmicosin was synthesized as a model compound for studying in vivo pharmacokinetics by ${ }^{19} \mathrm{~F} \mathrm{NMR} .{ }^{\dagger \dagger}$
20-Deoxo-20-(3,5-bis(trifluoromethyl)piperidinyl)desmycosin (2) was selected as a convenient target for synthesis. The presence of six fluorine atoms per molecule would provide the advantage of a stronger ${ }^{19} \mathrm{~F}$ NMR signal. In order to synthesize 2 from desmycosin (4), an efficient synthesis of 3,5-bis(trifluoromethyl)piperidine (3) was required.

\section{Results}

Attempts to prepare 3 from 2-hydrazino-3,5-bis(trifluoromethyl)pyridine (5) by first removing the hydrazine moiety by known oxidative methods using silver acetate or yellow mercuric oxide were unsuccessful in forming the intermediate 3,5-bis(trifluoromethyl)pyridine (6). ${ }^{3,4)}$ The literature reported that 2-chloropyridine derivatives could be dehalogenated over $5 \%$ palladium on carbon,

Fig. 1. The structures of tilmicosin $\left(1 ; R=H_{3}\right)$ and its hexafluoro-analog $\left(2 ; \mathrm{R}=\mathrm{F}_{3}\right)$.

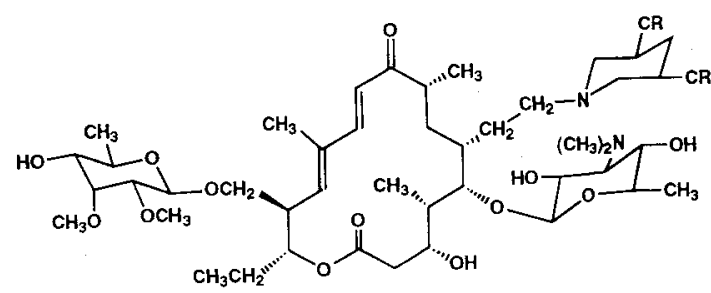

+ This publication is dedicated to Professor Satoshi ŌMura in honor of his 60th birthday.

${ }^{i \dagger}$ Some of this material was presented at the 34th Interscience Conference on Antimicrobial Agents and Chemotherapy, Orlando, Florida, October 1994, abstract number F170. 
and pyridine derivatives could be hydrogenated to piperidine derivatives over platinum oxide. ${ }^{5,6)} \mathrm{We}$ found that commercially available 2-chloro-3,5-bis(trifluoromethyl)pyridine (7) could be dehalogenated and hydrogenated to produce the desired product 3 in one step using a 1:10 mixed catalyst of $5 \%$ palladium on carbon and platinum oxide, respectively, in ethanol. This ethanolic solution of 3 was then mixed with desmycosin and treated with sodium cyanoborohydride to

Fig. 2. Synthesis of 3,5-bis(trifluoromethyl)piperidine.<smiles>NNc1ncc(C(F)(F)F)cc1C(F)(F)F</smiles>

[5]<smiles>C=CCCC</smiles><smiles>FC(F)(F)c1cnc(Cl)c(C(F)(F)F)c1</smiles>

[7] give the desired reductive amination product 2 .

The proton NMR spectrum of $\mathbf{2}$ was identical to that of tilmicosin except that the doublets at 0.80 and 1.00 ppm for the methyl groups of the dimethylpiperidinyl moiety were missing, and the multiplet at $0.50 \mathrm{ppm}$, which corresponds to one of the methylene protons at C-4 of the piperidinyl ring, had been shifted downfield. ${ }^{7)}$

Fig. 3. Synthesis of hexafluoro-analog of trilmicosin.

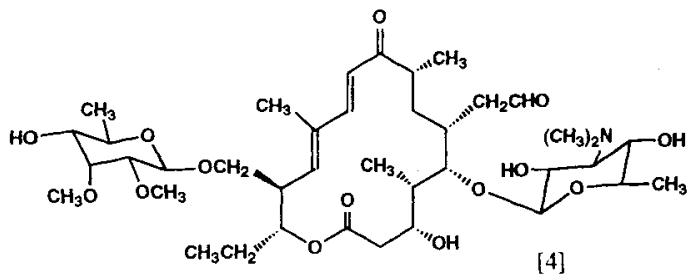

[4] $\mathrm{EtOH}$

Fig. 4. The ${ }^{1} \mathrm{H}$ NMR $(300 \mathrm{MHz})$ of tilmicosin (1) in $\mathrm{CDCl}_{3}$ referenced to TMS.

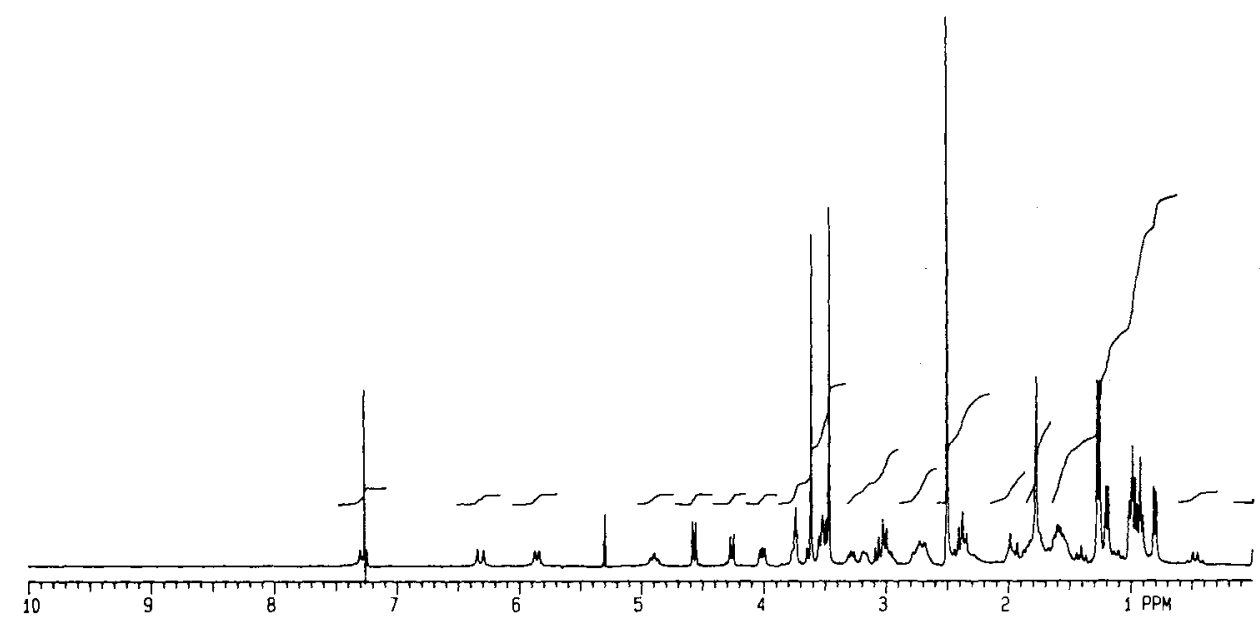

Fig. 5. The ${ }^{1} \mathrm{H}$ NMR (300 MHz) of hexafluoro-analog (2) of tilmicosin in $\mathrm{CDCl}_{3}$ referenced to TMS.

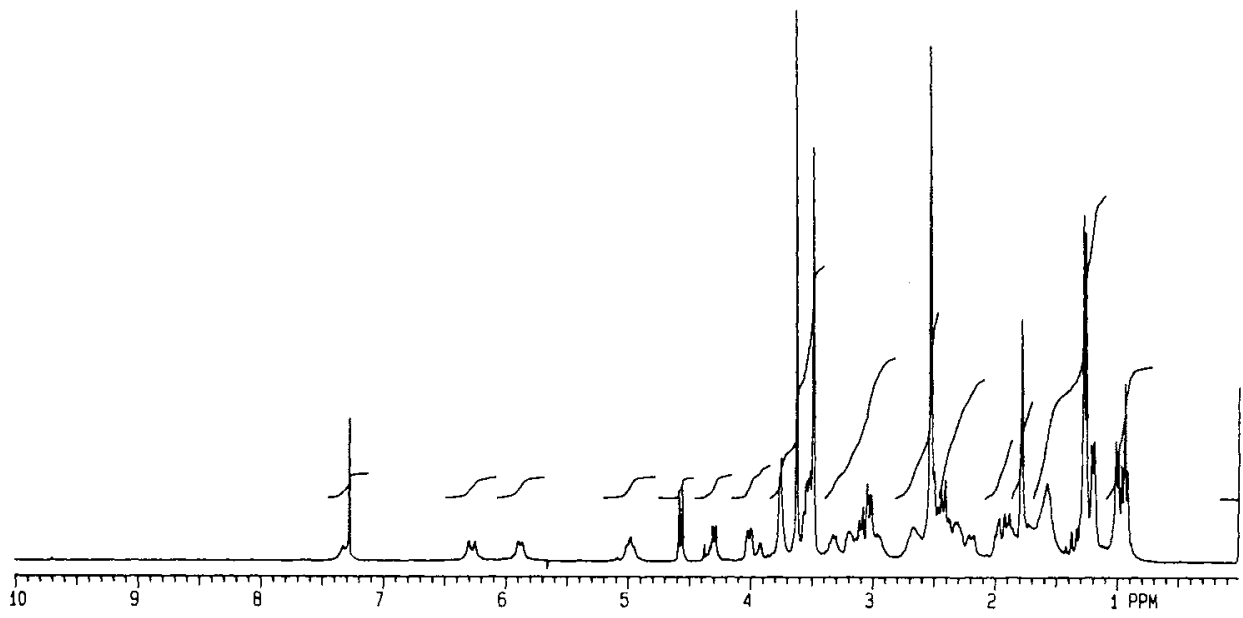


Fig. 6. The ${ }^{19} \mathrm{~F}$ NMR $(282 \mathrm{MHz})$ of hexafluoro-analog (2) of tilmicosin in water-ethanol $(20: 1 \mathrm{v} / \mathrm{v})$.

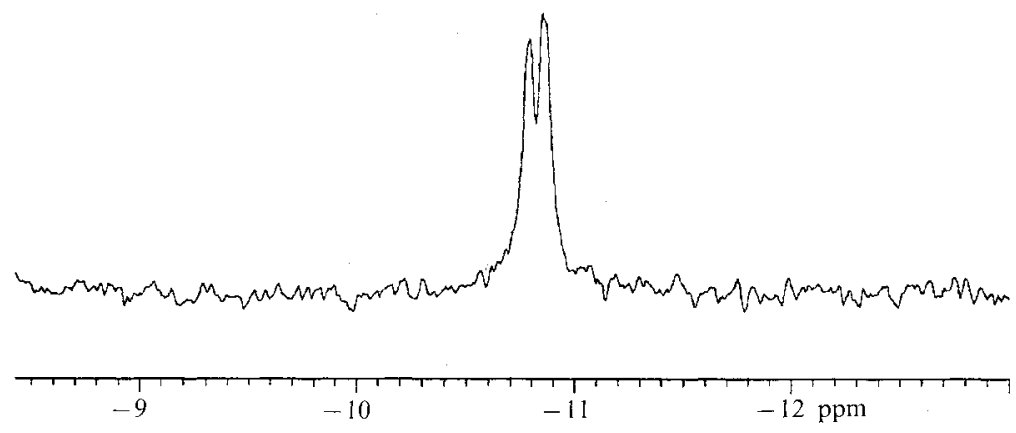

Table 1. In vitro MIC values (in $\mu \mathrm{g} / \mathrm{ml}$ ) for tilmicosin (1) and hexafluorotilmicosin (2).

\begin{tabular}{|c|c|c|c|c|c|c|c|}
\hline Organism & Strain & (1) & (2) & Organism & Strain & (1) & (2) \\
\hline \multirow[t]{5}{*}{ Staphylococcus aureus } & $\mathrm{X} 1.1$ & $<0.25$ & $<0.25$ & \multirow[t]{3}{*}{ Pasteurella haemolytica } & $128 \mathrm{~K}$ & nd & 8 \\
\hline & V41 & $<0.25$ & $<0.25$ & & $129 \mathrm{R}$ & 2 & 2 \\
\hline & $\mathrm{X} 400$ & $<0.25$ & $<0.25$ & & $133 \mathrm{~A}$ & nd & 8 \\
\hline & F15R & nd & 16 & \multirow[t]{6}{*}{ P. multocida } & $60 \mathrm{~A}$ & 6.25 & 32 \\
\hline & SI3E & $<0.25$ & $<0.25$ & & $77 \mathrm{G}$ & nd & 32 \\
\hline \multirow[t]{5}{*}{ S. epidermidis } & 270 & 128 & 128 & & $108 \mathrm{E}$ & 2 & 64 \\
\hline & 222 & $<0.25$ & $<0.25$ & & $116 \mathrm{E}$ & nd & 16 \\
\hline & F5C & nd & 1 & & $129 \mathrm{M}$ & bd & 8 \\
\hline & $92 \mathrm{E}$ & nd & 0.5 & & 1411 & 2 & 16 \\
\hline & F5R & $<0.12$ & 1 & \multirow[t]{3}{*}{ Escherichia coli } & $\mathrm{EC14}$ & 64 & 128 \\
\hline Streptococcus pyogenes & $\mathrm{C} 203$ & 1 & 16 & & TEM & 4 & 128 \\
\hline S. pneumoniae & PARK & 1 & 8 & & $28 \mathrm{C}$ & $>64$ & $>256$ \\
\hline \multirow[t]{2}{*}{ Enterococcus faecium } & $\mathrm{X} 66$ & 1 & 4 & \multirow[t]{2}{*}{ Klebsiella pneumoniae } & $\mathrm{X} 26$ & 8 & 128 \\
\hline & 2041 & 2 & 8 & & $\mathrm{X} 68$ & 128 & 128 \\
\hline \multirow[t]{2}{*}{ Haemophilus influenzae } & C.L. & 2 & 32 & \multirow[t]{4}{*}{ Salmonella sp. } & X514 & 32 & 128 \\
\hline & 76 & 2 & 16 & & 1335 & 64 & 128 \\
\hline \multirow[t]{2}{*}{ Pasteurella haemolytica } & $115 B$ & 8 & 32 & & $33 \mathrm{C}$ & 64 & $>256$ \\
\hline & $119 \mathrm{E}$ & nd & 16 & & $66 \mathrm{~B}$ & $>64$ & $>256$ \\
\hline
\end{tabular}

The mass spectrum and elemental analysis were both correct for 2. The fluorine NMR showed a doublet at $-10.8 \mathrm{ppm}$ with a splitting of $17.5 \mathrm{~Hz}$.

The fluorinated derivative 2 exhibited good activity against strains of staphylococci, but was less active than tilmicosin against streptococci and Gram-negative cocci. It was relatively inactive against Enterobacteriaceae and Pseudomonas species.

To explore how well 2 modeled the in vivo efficacy of tilmicosin, a disease challenge model with $P$. multocida strain 60A in 3-day old chicks was conducted. However, 2 failed to show any protection from the infection at $64 \mathrm{mg} / \mathrm{kg} \mathrm{sc}$ while tilmicosin afforded protection at $32 \mathrm{mg} / \mathrm{kg} \mathrm{sc}$. This result was in accord with the in vitro, MIC values which showed that 2 was only $1 / 5$ as active as tilmicosin against $P$. multocida strain $60 \mathrm{~A}$. An in vivo challenge study against a more sensitive organism such as $S$. aureus needs to be conducted to more accurately assess the relative in vivo efficacy of $\mathbf{2}$ and tilmicosin.

Despite the lack of in vivo activity against the
Pasteurella challenge, an initial experiment was performed to assess the feasibility of in vivo ${ }^{19} \mathrm{~F}$ NMR spectroscopy. 2 was administered ip at $50 \mathrm{mg} / \mathrm{kg}$ in a $2 \%$ EtOH-saline buffer solution with a trace amount of tartaric acid to an anesthetized female Sprague-Dawley rat (approximately $250 \mathrm{mg}$ body weight). The fluorine spectrum was acquired using a $2.7 \mathrm{~cm}$ diameter transmit/ receive single turn surface coil. The pulse delay was set to 3 seconds and 256 transients were acquired. Exponential line broadening of $50 \mathrm{~Hz}$ was applied to the time domain data. Accumulation was recorded in the liver one hour post administration. Although the lineshape of the fluorine resonance was broadened and the resolution was reduced by paramagnetic susceptibility effects due to the naturally high levels of iron in the liver, a strong signal was received. No signals were detected in the in vivo ${ }^{19} \mathrm{~F}$ NMR scan before the administration of 2. Shift differences were noted between the in vivo ${ }^{19} \mathrm{~F}$ NMR and the analytical ${ }^{19} \mathrm{~F}$ NMR due to the use of different data acquisition parameters on different field 
Fig. 7. The in vivo $F$ NMR spectrum of $\mathbf{2}$ in the female Sprague-Dawley rat liver 1 hour post ip administration.

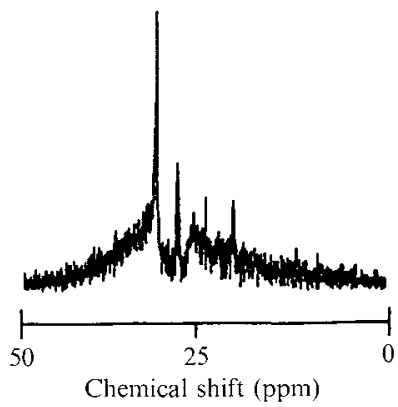

strength instruments.

In conclusion, a fluorinated analog of the antibiotic tilmicosin has been synthesized and detected in vivo by ${ }^{19} \mathrm{~F}$ NMR spectroscopy. This successful preliminary experiment suggests that ${ }^{19} \mathrm{~F}$ NMR may be a useful tool for non-invasive pharmacokinetic studies. Future studies are needed to look for detectable signals from other tissues and organs, to follow the signals for a longer time course, to determine concentrations, and to determine if 2 is an accurate pharmacokinetic model for tilmicosin.

\section{Experimental}

General Procedures

${ }^{1} \mathrm{H}$ NMR spectra were measured in $\mathrm{CDCl}_{3}$ solution on a Varian Gemini-300 spectrometer and are scaled from internal TMS. The analytical ${ }^{19} \mathrm{~F}$ NMR spectrum was measured in water-ethanol $(20: 1)$ solution on a 7 Tesla GE/Tecmag spectrometer at a frequency of 282 $\mathrm{MHz}$ for fluorine. The ${ }^{19} \mathrm{~F}$ NMR in vivo spectrum was measured at 4.7 Tesla on a Spectroscopy Imaging Systems Corporation (SISCO) imager/spectrometer with a custom built single loop surface coil tuned to $188 \mathrm{MHz}$ for fluorine. IR spectra were obtained on a Nicolet 510P Optical Bench spectrometer. UV spectra were measured on a Shimadzu UV-2101 PC Spectrophotometer. Field desorption mass spectra (FD-MS) were obtained on a VG ZAB-3F mass spectrometer. Elemental analyses were performed on a Control Equipment Corporation 440 elemental analyzer for carbon, hydrogen and nitrogen. Elemental analyses for fluorine were measured using a Dr. Hans Hosli, Model A-1 furnace, a Brinkmann 665 Dosimat titrator and a Brinkmann PC/100 colorimeter.

The preparation of desmycosin was carried out at the Lilly fermentation facilities at Indianapolis, IN, U.S.A. 2-Chloro-3,5-bis(trifluoromethyl)pyridine and sodium cyanoborohydride were obtained from Aldrich Chemical Co., Milwaukee, WI, U.S.A.. 2-Hyrazino-3,5-bis(trifluoromethyl)pyridine was obtained from Ryan Scientific Co., Columbia, SC, U.S.A.

Antibiotic susceptibility data were obtained by broth or agar dilution procedures (Table 1). Determination of in vivo activity against an infection caused by Pasteurella multocida strain $60 \mathrm{~A}$ was conducted with 3-day old chicks which were acclimated overnight with ad libitum access to feed and water. After two days of observation, the birds were inoculated intramuscularly in the thigh with $0.1 \mathrm{ml}$ of $10^{7} \mathrm{cfu} / \mathrm{ml} \quad P$. multocida strain $60 \mathrm{~A}$ (cultured in Columbia broth at $37^{\circ} \mathrm{C}$ ). The birds were subcutaneously administered compounds $\mathbf{1}$ and 2 (solubilized in DMSO) at 1 and 4 hours post-challenge. The birds were observed through Day 10 post treatment.

20-Deoxo-20-(3,5-bis(trifluoromethyl)piperidinyl)desmycosin (2)

To a solution of $7(5.0 \mathrm{~g}, 20.04 \mathrm{mmol})$ in EtOH $(140 \mathrm{ml})$ was added $5 \%$ palladium on carbon $(0.5 \mathrm{~g})$ and platinum oxide $(5.0 \mathrm{~g})$, and the suspension was placed under hydrogen gas ( $60 \mathrm{psi})$ at $60^{\circ} \mathrm{C}$ for 6 hours. The catalysts were then removed by filtration, and desmycosin $(11.04 \mathrm{~g}$, $14.0 \mathrm{mmol}$ ) was added. After stirring the mixture at room temperature for 45 minutes, $\mathrm{NaBH}_{3} \mathrm{CN}(1.18 \mathrm{~g}, 19.0$ mmol) was added and the solution was stirred an additional 5 hours at room temperature. The solvent was evaporated at room temperature under vacuum, and the residue was chromatographed on silica gel, eluting with $\mathrm{MeOH}$, to give crude $2(14.6 \mathrm{~g})$ as an off-white solid. A pure sample of 2 was obtained by suspending the crude product $(9.58 \mathrm{~g})$ in $\mathrm{pH} 2$ buffer $(400 \mathrm{ml})$ and filtering. The filtrate was then basified with $5 \mathrm{~N} \mathrm{NaOH}$, saturated with $\mathrm{NaCl}$, and extracted with EtOAc. The EtOAc was washed with brine, dried $\left(\mathrm{MgSO}_{4}\right)$ and evaporated at room temperature to give pure 2 (4.01 g); FD-MS $m / z$, $977\left(\mathrm{M}^{+}\right) ; \mathrm{UV} \lambda_{\max } \mathrm{nm}(\varepsilon) 282(21,807) ; \mathrm{IR}\left(\mathrm{CHCl}_{3}\right)$ $\mathrm{cm}^{-1}, 3029,2975,2937,2881,1730,1592,1456,1378$, $1314,1289,1254,1166,1129,1081,1058,1008,985,962$; ${ }^{1} \mathrm{H}$ NMR $\left(\mathrm{CDCl}_{3}\right)$, Fig. 5 .

$$
\begin{aligned}
& \text { Anal Calcd for } \mathrm{C}_{46} \mathrm{H}_{74} \mathrm{~F}_{6} \mathrm{~N}_{2} \mathrm{O}_{13} \text { : } \\
& \mathrm{C} 56.55, \mathrm{H} 7.63, \mathrm{~N} 2.87, \mathrm{~F} 11.67 \\
& \text { Found: } \mathrm{C} 56.82, \mathrm{H} 7.88, \mathrm{~N} 2.95, \mathrm{~F} 9.39
\end{aligned}
$$

\section{Acknowledgments}

We thank J. Paschal for helpful assistance on ${ }^{1} \mathrm{H}$ NMR interpretation, and T. PARR for helpful discussions which led to this study. We also thank the Physical Chemistry Department and the Infectious Disease Core Group of Eli Lilly and Company for characterization and test data, and BILl Cummings, Dennis Ulrey, and J. Mitchell Staples for technical assistance.

\section{References}

1) BRyskner, A. \& J.-F. Chantot: Pharmacokinetic behavior of macrolide antibiotics in animals. In Macrolides: Chemistry, Pharmacology, and Clinical Uses. Eds. A. J. Bryskier, J.-P. ButzleR, H. C. Neu, P. M. Tulkens, pp. $341 \sim 375$, Arnette Blackwell, Paris, 1993

2) KIRST, H. A.: Chapter 5. Semi-synthetic derivatives of 16-membered macrolide antibiotics. In Progress in Medicinal Chemistry Vol. 31. Ed. G. P. ElLIs, et al., pp. 
265 295, Elsevier Science B.V., Amsterdam, 1994

3) PlazeK, E.: Ueber Eine Synthese des 3,5-Dinitropyridins. Rec. Trav. Chim. Pays-Bas 72: 569 575, 1953

4) Albert, A. \& G. Catterall: Oxidative replacement of the hyrazino-group by hydrogen and deuterium in azanaphthalenes. J. Chem. Soc. (C): 1533 1541, 1967

5) SChreiber, K.\& A. Günter: Eine neue Eifache Synthese der Fusarinäsure. Chem. Ber. 93: $1848 \sim 1851,1960$
6) Snow, R. J. \& L. J. Street: Synthesis of 3,5-disubstituted 1-azabicyclic systems: Intermediates for novel muscarinic ligands. Tetrahedron Lett. 30: 5795 5798, 1989

7) Krrst, H. A.; A. L. Donoho, L. C. Creemer, J. A. Wind, D. M. Berry, J. L. Occolowitz \& J. W. Paschal: Identification and synthesis of products isolated during metabolism studies of tilmicosin. J. Agric. Food Chem. 42: $1219 \sim 1222,1994$ 